\title{
Online Orchestra: Connecting remote communities through music
}

\begin{abstract}
Online Orchestra is a telematic performance project, aimed at enabling young and amateur musicians in geographically remote locations to make music together over the Internet. This article describes the contexts out of which the project emerged, including an overview of the benefits of ensemble performance, and a survey of precedent telematic performance projects. It goes on to describe how the starting premises of Online Orchestra respond to these contexts and ends with a summary of Online Orchestra's approach, and its key findings. The article describes in particular how many recent telematic performance projects rely on specialist networks and equipment, and that alternative design solutions are necessary, and possible, in order to reach young and amateur musicians in their own remote locations.
\end{abstract}

\section{Introduction}

Participation in ensemble performance has been shown to bring about wideranging personal, social and musical benefits. Yet in parts of the United Kingdom such as Cornwall, where young and amateur musicians often live in

\section{KEYWORDS}

Online Orchestra telematic performance remote locations community ensemble latency 
1. See also Higgins (2012); McKay and Moser (2005). geographically remote locations, access to ensemble performance opportunities can be limited. Online Orchestra was an Arts and Humanities Research Council-funded research project that asked how we can use burgeoning network technologies and creative approaches to composition to give people in remote communities access to large-scale ensemble music-making.

This article introduces the contexts in which the Online Orchestra project took place, including a brief overview of evidence for the benefits of ensemble performance, the opportunities of those living in remote locations with respect to ensemble music-making and precedent projects in the field of telematic performance. These contexts lead to a series of starting premises on which the project is based. The article ends with an overview of the project and a summary of its key findings. Details of different parts of the project are considered in greater depth in subsequent articles in this special issue.

\section{Benefits of ensemble music-making}

The benefits of participating in music ensembles, and of group music-making in general, have been well documented. Positive impacts come in a range of forms, including benefits to an instrumentalist's technique and creativity, the establishment of connectedness and intimacy that helps promote positive social interactions and builds a sense of community, and benefits to individuals' psychological well-being. In their 2011 study, Kokotsaki and Hallam ask two questions of non-music university students: 'How do you perceive your past or current involvement in musical ensembles?' and 'What impact did it have on you?' (Kokotsaki and Hallam 2011: 152). Their findings indicate perceived effects in three key areas: social impact, personal impact and musical impact (Kokotsaki and Hallam 2011: 153). These categories serve as a useful framework for an overview of the benefits that ensemble music-making might bring about.

\section{Social impacts}

The role that musical ensembles play in creating a sense of community, and providing benefits to society as a whole, has been explored in a wide range of studies. An early definition of a musical community came from the International Society of Music Education's (ISME) Community Music Activity commission in 1990:

Community music is characterised by the following principles: decentralisation, accessibility, equal opportunity, and active participation in music-making. These principles are social and political ones, and there can be no doubt that community music activity is more than a purely musical one.

(Olseng 1990 cited in McKay and Higham 2011: 5)1

That these principles have more to do with sociality than music per se (see Paton 2011: 117-18) is an important aspect of music's ability to function in a way that promotes social and community bonds. Noting the inclusion and cohesion' that is required in order to function as a performing group, Pitts concludes that

Making music with others was shown to affirm a sense of belonging and like minded endeavour, so sustaining commitment and offering 
a shared experience that fostered memories and friendships amongst a diverse group of people [...] Membership of a performing society requires each individual to work within a complex social structure; shaping, responding to or challenging agreed conventions and behaviours, and balancing the desire for personal fulfillment with a broader responsibility to the group. Finding a valued role within a musical society can fulfill the diverse needs of members from a variety of different social circumstances.

The ability of ensembles to create a sense of community for those in a wide variety of social circumstances has been examined. Blandfold and Duarte's study of community music centres in England and Portugal concludes that 'musical and social skills were significantly developed through participation in a musical community' (2004: 7; see also Renshaw 2005). Weston and Lenette examine the role music had on creating a sense of community in a refugee detention centre, concluding that

[...] the concept of 'community' is a complex and multifaceted one; we do not wish to oversimplify this construct here by suggesting that there was one, single community as defined by the walls of the detention centre. Nevertheless, through in-depth analysis of these narratives, it became clear that music-making in a detention centre created a 'community within a community' through the formation of a cultural and performative space.

(Weston and Lenette 2016: 123, original emphasis)

Carlucci, in a study of the New Horizons ensemble, notes that adult learners felt that participating in a musical ensemble increased their perception of support, and brought about'social bonds':

Results indicate that the majority of survey participants perceive support to be available 'most' or 'all of the time' in the categories of Instrumental/ Tangible Support (35.7\%), Companionship Support (38.1\%) and Emotional/Informational Support (41.1\%). Open-ended responses demonstrated specific examples of support being offered and received among participants. The results of this study indicate that in addition to being a musical outlet for adult learners, group music-making organizations such as New Horizons may be a viable way to increase and maintain social bonds across the lifespan.

(Carlucci 2012: 237)

Gembris' study of participation in ensembles in later life notes that '[t]he paramount reward of making music is an increase in enjoyment of life, quality of life, and happiness, and furthermore the establishment of social contacts, a sense of community, and challenges' (2008: 103).

Projects such as these demonstrate the power of music-making to overcome isolation, since, as Jones suggests, '[m] usic's inherently social nature helps people develop the kinds of social capital that can combat isolation and build crucial social networks' (Jones 2010: 292). Not only that, but such benefits 
can have a positive impact on the growth and attractiveness of communities where such activities take place:

Arts and culture not only attract creative workers but also have a positive impact on the community [...] Researchers at the University of Pennsylvania's Social Impact of the Arts Project found that the presence of arts and culture offerings in a neighborhood has a measurable impact on the strength of the community [...] causing residents to view their neighborhoods positively and engage in other forms of community involvement.

(Jones 2005: 5-6)

This capacity of music-making to promote and strengthen community cohesion, as well as cultural capital and growth, has been widely discussed (see Gibson et al. 2010; Roberts and Townsend 2015; Duxbury and Campbell 2011; Thomas et al. 2013; Bell and Jayne 2010; McHenry 2011). Moreover, advances in technology may offer communities new opportunities in these regards. As McKay and Higham note, digital music technology is potentially'democratizing' and 'cool', and so potentially more inclusive of the young (2011: 8). It also helps to overcome 'the community arts model of community as located - and is predicated on "the congregationalist imperative"' (McKay and Higham 2011: 8; see also Dillon and Brown 2010): an advantage that is particularly germane to the aims of Online Orchestra, as will be seen.

\section{Personal impacts}

The benefits of group music-making on the individual are often identified as those that improve aspects of health and well-being. Evaluating the 'Good Vibrations' project, which involved prisoners participating in gamelan ensembles, Wilson et al. observe that long-term effects include

Greater levels of engagement and an increased openness to wider learning; improved listening and communication skills; improved social skills and increased social interaction; improved relationships with prison staff; and decreased levels of self-reported anger and a greater sense of calmness.

(2008: 3)

A study on the effects of participatory group music-making in elderly residents of nursing homes by Vanderack et al. shows significant improvements for participants in the areas of 'life satisfaction, music attitude, and self-concept in music' (Vanderack et al. 1983: 71). Weston and Lenette note the "links between the "community" created through participatory music in a detention centre context, and the specific role music-making played within those parameters to enhance the participants' sense of wellbeing' (2016: 123). Bailey and Davidson likewise observe that '[a]ctive participation in singing may act to alleviate depression, increase self-esteem, improve social interaction skills and induce cognitive stimulation' (2002: 221). Performing can also enhance individuals' self-esteem and self-confidence, as one study into those performing in rock bands found: 
Performing in public was a means of gaining self-confidence, selfrespect, and the respect of others, and people were frequently said to have changed personality and become more outgoing through membership of a band.

(Pitts 2004: 144)²
2. For a wider review of the personal benefits of active music making see Hallam et al. (2012).

\section{Musical impacts}

Kokotsaki and Hallam (2011) note the perceived benefits that playing in an ensemble can have upon participants' musicianship. This includes

[...] making progress in their playing and technique (13\%), enhancing the development of sight-reading skills and general musicianship (7\%) and becoming more confident performers $(10 \%)$. The experience also enhanced more general engagement with music, raising their listening skills in relation to the music itself and their ability to better engage aurally with co-performers (10\%).

(Kokotsaki and Hallam 2011: 156)

McCaleb likewise describes the way that group music-making can involve stretching musicians' abilities beyond what is possible in solo performance:

Those playing share a connectedness and an intimacy that surpasses many other social interactions. Individual musicians' interpretations build upon each other to create an aesthetic whole that may be much greater than the sum of its parts. Unexpectedness and spontaneity can spark the most exciting performances, pushing the ensemble members to the boundaries of their technical and creative abilities.

Moreover, Bailey and Davidson note that the capacity of music to bring about these positive changes transcends musical ability: 'active participation in music may have adaptive characteristics at many levels of proficiency' (2002: 221).

It is not only musical ability in itself that can be enhanced by playing in an ensemble: the motivation to engage in music-making has also been shown to be augmented. Kokotsaki and Hallam note the significant number of their participants who 'developed increasing motivation to further engage with music and music making (21\%)' (2011: 161); Pitts likewise notes that attending a musical summer school 'appears to provide an impetus and renewed enthusiasm for many participants' (2005: 39), and that 'Participation in musical activities has the potential to satisfy individual motivations and goals, with new aspects of learning and self-discovery enriching the lives of participants in a variety of ways' (Pitts 2005: 33).

\section{Participation and the challenge of geographical remoteness}

Given the wide-ranging potential benefits of ensemble performance, several recommendations in the 2011 Henley Review into Music Education describe the need for ensemble performance in music education: for instance, recommendation seven states that 'children should have the opportunity to take part in 
vocal and instrumental ensembles. These should either be offered in schools or by bringing pupils together from schools in a wider locality' (2011: 13). This resulted in the recommendation in the UK Government's National Music Plan that 'Children from all backgrounds and every part of England should have the opportunity [...] to make music with others' (Department for Education 2011: 7) because 'When young people make music together, they work toward a common goal that has the potential to change lives profoundly for the better' (Department for Education 2011: 4).

However, young and amateur musicians living in geographically remote communities often do not have access to ensemble music-making opportunities - the time, expense or logistics of travel can make participation on a regular basis impossible. Five Islands' School on the Isles of Scilly offers a useful case study on the challenge of geographical remoteness. The school provides primary and secondary education (ages 3-16) at five sites across the Isles of Scilly, amounting to some 275 pupils in total in 2015. Its music provision is well developed, thanks to a series of music heads who have maximized the available resources in order to establish significant programmes of instrumental lessons and ensembles/choirs, on top of GCSE-level music teaching.

However, with a permanent population of just over 2200 people on the islands, there are simply not enough specialist instrumental teachers to provide full coverage of instrumental lessons. The reality in the 2014-15 cycle was that only flute, clarinet and saxophone lessons could be offered on a regular basis in the school, meaning those children wanting to learn an instrument were forced to take up one of these options. This in turn has led to schoolwide instrumental ensembles being limited to flute choir and wind group. No regular provision of string and/or brass instrument teaching or ensemble performance is possible.

What exists at Five Islands' School might usefully be described as a community of practice. A term coined in 1991 by Jean Lave and Etienne Wenger (1991), Wenger has more recently defined communities of practice as 'groups of people who share a concern or a passion for something they do, and learn how to do it better as they interact regularly' (Wenger-Trayner and Wenger-Trayner 2015: 1). He goes on to describe three primary criteria: communities of practice have 'a shared domain of interest', 'engage in joint activities and discussions' and 'are practitioners' (Wenger-Trayner and Wenger-Trayner 2015: 2). In the case of Five Islands' School, this is particularly pertinent, for not only does the flute tutor teach children at the school, she also teaches the head of music, and a number of the children's parents. A close-knit and productive community of practice has thus emerged, centred around and stimulated by the presence of a key individual: the flute teacher.

However, for those who learn flute, and indeed other wind instruments, at Five Islands' School, it is simply not possible to gain experience of playing in larger ensembles. To access a full orchestra would involve travelling to Penzance - a $2 \frac{1}{2} 2$-hour boat crossing (that does not run over winter) or a $£ 70$ flight to the main land (the timetable for which does not always tally with the school day and does not run on Sundays), followed by a 30-minute bus ride to the nearest large town. As such, it is clearly not practical to participate in mainland orchestral music-making on any kind of regular basis. In the absence of island-based activities, this significantly limits the prospects of those children with musical ambitions living on the islands. Deborah 
Wainwright, Head of Music at Five Islands' School, frames the problem in terms of opportunity:

I would like my children to have a level playing field. I would like them to have the same opportunities as children on the mainland so that when they start competing for university places, they have the same background.

(interview)

Whilst the Isles of Scilly present an extreme case of geographic remoteness in the United Kingdom, the situation is mirrored across the country, particularly in rural parts of Scotland, Wales, the South West of England and the North of England. A similar community of practice exists, for instance, on the Lizard Peninsula in Cornwall, where an exceptionally high-quality brass band has emerged in St Keverne. As such, many children in the local area learn brass instruments with members of the band and its inspiring conductor, and then ultimately graduate to participating in the band. Again, access to lessons on other instruments is more difficult, as tutors have to travel significant distances to reach pupils: in reality, it is the pupil who has to travel.

\section{Telematic performance: A potential solution?}

Telematic performance - broadly defined as performance that takes place over telecommunications networks such as the Internet - has the distinct capacity to enable those in remote locations to make music with others: in theory, musicians anywhere in the world could, given appropriate equipment, connect together and make music online. This in turn could, in theory, enable increased access to the range of benefits, outlined above, that can result from participation in ensemble music-making (see Oliver and Reeves 1994). Telematic performance has a long and varied history, and it is useful to consider a range of projects from which Online Orchestra drew learning, and on which it builds.

\section{Antecedents to telematic performance}

Communicating music over distance long precedes what now might be thought of as telematic performance. In 'The telematic music system: affordances for a new instrument to shape the music of tomorrow', Braasch states that 'Telematic music has always been a part of our cultural life' (2009: 421). Citing Fitch and Koehler (1951) on bird song and the origins of human music, he suggests that 'it is clear that we were exposed to some from of telematic music right from the beginning, since an important aspect of birdsong is the communication over long distances' (Braasch 2009: 421).

As long ago as the sixteenth century, multi-nodal choir arrangements were used in which 'Acoustics were first put to resonant effect by the use of "cori sprezzi", the choir distributed in galleries' (Joy 2009: 453). Examples include: Missa supra Ecco si beato giorno (1565) by Alessandro Striggio, which has 60 separate voice parts, distributed among twelve-part choirs, in five discrete nodes; and Spem in alium nunquam habui (1570) by Thomas Tallis, which has music for eight choirs of five voices each (Joy 2009: 453-55). Musicians in different locations thus work together in the performance of a single composition. 
3. The challenge posed by latency is considered in more detail in Rofe and Reuben (2017), in this special issue.

\section{Pre-Internet telematic performance}

Citing Steinberg and Snow's (1934) description of an event in which the Philadelphia Orchestra broadcast their music live to Washington DC, Braasch notes that distributed music-making quickly followed the advent of telecommunications, and indeed that early analogue telephone lines were'not characterized by the large system latencies that plagued early digital systems' (2009: 429). ${ }^{3}$ Although the concert was designed to be an extension of the concert hall, interaction at the remote site was possible.

Kim-Boyle identifies post-war collaborative performances by Stockhausen (1959), Brown (1965), Haubenstock-Ramati (1965), Wolff (1987) and Brün (2004), as well as improvising collectives AMM and MEV as precursors to contemporary telematic performance (2009: 363ff). These performances were influenced by the Fluxus School and were investigating, to various degrees, situating the audience in performative roles: 'Just as much of the work of this earlier generation was motivated by social and political ideals, composers of network-based music often share a common interest in democratizing performance [...]' (Kim-Boyle 2009: 364). These precursors to contemporary telematic performance had at their core an idea of the network as metaphor for political hierarchy and instability.

Between 1966 and 1977, Max Neuhaus produced a series of pieces termed 'Broadcast Works' which are 'amongst some of the earliest work to utilize telecommunications networks for artistic purposes' (Kim-Boyle 2009: 364). In many cases, the musical output is dependent on input from the audience: for Public Supply I (1966), for instance, Neuhaus invited radio listeners to call in and produce any sounds they wished; he would then mix this into a musical composition, mediating the relationship between participants via the mixing process, thereby'reinforcing musically interesting dialogues while downplaying those of less appeal' (Kim-Boyle 2009: 365).

\section{Early computer networks}

In 1977, the League of Automatic Music Composers '[...] employed computers to exchange messaging data between each player in order to make music in a networked environment' (Schroeder 2009: 378). The group was active between 1978 and 1983; in 1986 they formed the HUB, whose name was derived from the use of a central computer acting as a networking hub connecting all computers. These groups are considered to have created the first computer-networked music (Schroeder 2009: 378). As Traub notes, 'The initial HUB concert, held in 1987, took place in New York and connected six performers, divided between two venues, joined by a 300-baud modem network' (2005: 466). In 1987, there was a link-up of simultaneous concerts between Graz, Ljubljana and Trento called 'Razionalnik': this was similar to League of Automatic Music Composers and the HUB in that performers were sharing control data rather than audio; however, the HUB designed specialist network infrastructures, whereas the 'Razionalnik' devisors'consciously worked within existing media space' (Föllmer 2005: 442). In any case, each of these examples demonstrates the emergent use of computers to facilitate multi-venue performance.

\section{Networking platforms}

From the early 1990s, dedicated networking platforms designed for telematic performance begin to emerge. Many of these were forced to grapple with the 
issue of latency - the short time delay involved in processing data and sending it over the network. In 1990, Richard Magill at the University of Michigan developed the platform 'NetJam' as a means to distribute messages and files over a network. It was not at this stage intended for real-time performance, but rather facilitated collaboration by sending MIDI messages and other control data: 'Musicians were able to edit these files and send them back to anybody in the network community who had MIDI-compatible equipment as well as email and internet access' (Schroeder 2009: 378). Soon after, in 1991, Tim Perkis, one of the founding members of the HUB, performed Waxlips, in which bursts of MIDI data from the lead performer were sent over a network, 'Triggering clusters of events and creating an audible change in sonic density as MIDI messages were dropped or failed to transmit between Hub performers. Waxlips was designed to highlight the failings of the network' (Traub 2005: 467).

In 1994, Rocket Network launched the 'Vortex Jamming' software, creating the concept of the MUSE (Multi-User Studio Environment). This concept was refined and made 'more real-time' (Schroeder 2009: 378) by Ruskin Software technology and their 'LiveJam' application. Users could select a room to join and make music with other participants all over the world. This is a direct precursor to the newer 'eJAMMING AUDiiO'. Headed by Alan Glueckman, eJAMMING is an audio-only platform that promises'to reduce the delay experienced over the network to, at most, hundreds of milliseconds (depending on upload speed and geographic distance between musicians) - a delay to which, Glueckman says, most musicians can adjust with practice' (Greene 2007). ${ }^{4}$

The development of high-speed Internet backbones such as Internet2 and Janet allowed for the real-time, high-quality transmission of audio over the network. The SoundWIRE Project, led by Chris Chafe at the Centre for Computer Research in Music and Acoustics, Stanford, was an early adopter of Internet2, 'Thereby establishing the first platform that allowed for the realtime, high-quality uncompressed bi-directional audio streaming' (Schroeder 2009: 378). The SoundWIRE group 'focuses on experiments in bi-directional and n-directional musical performance. Concerts and rehearsals between Stanford and places like New York, Belfast, Banff, or Beijing are now commonplace' (Chafe and Cáceres 2010: 183). Cáceres and Chafe align their software, JackTrip, with 'high speed links like Internet2', stating that 'adequate network provisioning is a must' (2010: 183).

Another dedicated network platform is LOLA: LOw LAtency audio-visual streaming system. Its architects state that the 'LOLA project aims to enable real time musical performances where musicians are physically located in remote sites, connected by advanced network services like the ones provided by the NRENs and GEANT and other international backbones' (Pachini et al. 2012: 1). The LOLA project was developed by Conservatorio di Musica Giuseppe Tartini in collaboration with GARR, the Italian Research and Academic Network. LOLA has been used to facilitate a wide rage of performances ${ }^{5}$ using high-speed Internet connections such as Janet in the United Kingdom and Internet2 in the United States. As such, its low-latency approach is contingent on working in specialist institutions that are connected to these high-speed networks. UltraGrid adopts a similar approach, using high-speed networks to facilitate low-latency performances. ${ }^{6}$

\section{Educational, socially inclusive and participatory networks}

As can be seen, significant milestones in the history of telematic performance have tended to be driven either by composers or by technologists, giving rise
4. More commonly, 3oms is defined as the cut-off at which musicians can perceive latency; this is discussed in Rofe and Reuben (2017)

5. See http://www.conts it/art/lola-project/ lola-video

6. See http://www ultragrid.cz. 
7. This will be discussed in more detail in Rofe and Reuben (2017) in this special issue either to specific works designed for telematic performance or to networking platforms that are designed to push the technology to its limits and enable wide-ranging performance possibilities. Fewer examples exist that see the educational or social potential of telematic performance as a primary aim.

Examples do exist of network-based community composition. In 1999, 'Symphony for Cornwall', by Andrew Hugill, was performed at the Hall for Cornwall, Truro, by the Bournemouth Sinfonietta and accompanied by live electronics. Hugill was interested in the idea of 'networked creation' and 'the internet as a compositional medium' (2005: 528): secondary schools across Cornwall were invited to submit 10-15 second sound recordings of anything they chose, which Hugill used as 'seeds' from which to grow a composition. Likewise, Eric Whitacre's Virtual Choir asks singers to 'record and upload their videos from locations all over the world. Each one of the videos is then synchronised and combined into one single performance to create the Virtual Choir' (Whitacre 2017). In both cases, therefore, participants do not perform live together, making these works for networked and collaborative composition rather than networked performance. They do, though, demonstrate the capacity for networked music-making to reach out into communities.

A field of musical practice that has seen greater research and implementation in online contexts is musical instrument lessons. Many tutors now offer lessons over Skype, for instance, as a supplement or alternative to in-person lessons. Operational since 2001, Connect: Resound has explored through action research how online technologies might 'respond to consistent challenges to accessing music education among children in rural areas' (Johnson et al. 2015: 18). Using audio and video streaming, the project allows music teachers to instruct and perform remotely with students, and concludes of its participants that

Parents gave positive feedback about children's progress with $24.5 \%$ stating it was 'very good', $46.9 \%$ indicating it was'good', and $28.6 \%$ that progress was satisfactory. Most of the pupils (74.1\%) and many parents/ carers $(68.2 \%)$ wanted them to continue to learn their instruments'quite a lot' or 'very much'.

(Johnson et al. 2015: 10)

However, because Skype is often used as the underlying software interface, bi-directional, interactive music-making is not possible: Skype uses audio gating to suppress echo, meaning only one node can make sound at a time.

Other programmes of telematic musical instrument lessons have been offered at the Manhattan School of Music, New York, the Royal College of Music, London and the Royal Danish Academy of Music, Copenhagen. These have been enabled through the use of LOLA, which does offer bi-directional performance. However, as described above, LOLA requires high-speed network connections that are only currently available at these types of specialist institutions; they are not available in community venues, again limiting access and opportunity, even in the context of telematic performance. ${ }^{7}$

\section{Online Orchestra - Starting premises}

The Online Orchestra project, which took the form of a large-scale pilot, sought to realize the potential of telematic performance to address the lack of access and opportunity so frequently found in remote contexts. As described 
in the Introduction, the core research question is: 'How can burgeoning network technologies, and creative approaches to composition, be used to give people in remote communities access to large-scale ensemble performance opportunities?' As such, the project sought to investigate telematic performance solutions that might, with future refinement, enable musicians in remote communities to experience the well-documented potential benefits of ensemble music-making.

Online Orchestra was founded on a series of starting premises, each of which emerged from the contexts described above, and the subsequent core research question. Other premises could in theory give rise to very different design solutions, but those outlined below remained the guiding principles of all subsequent decision-making throughout the Online Orchestra project.

\section{Create new opportunities for young and amateur musicians}

The core aim of the project was to enable, through telematic performance, new ensemble music-making opportunities for young and amateur musicians. This is not, of course, to preclude professional musicians using Online Orchestra in the future; rather, in the light of the particular issues facing isolated communities of practice, it was decided that a design solution was needed that specifically enabled performers with lower musical ability to flourish. This contrasts with the majority of precedent telematic performance projects, which tend to involve professional musicians. More specifically, Online Orchestra aimed to reach musicians who do not normally have access to large-scale, musicmaking opportunities. The nature of those access constraints in the project were primarily geographical, but other constraints might in the future include mobility problems, financial limitations or confinement to particular locations (e.g. hospitals, care homes, prisons, etc.).

\section{Enable access from remote locations}

Online Orchestra aimed to design a solution in which musicians could participate from their own remote locations, rather than having to travel somewhere further afield in order to take part. Indeed the larger potential of telematic performance is fundamentally rooted in this principle: that musicians anywhere in the world could perform together, assuming the availability of suitable equipment (see below). This in turn required a solution that could work using existing broadband connections - the types of high-speed network required by specialist software such as LOLA and UltraGrid are not currently available in community contexts.

\section{Design a scalable solution}

As a pilot, Online Orchestra aimed to design a solution that could be scalable, enabling a wide range of potential future users. A design solution that was not contingent on overly expensive, or overly complex, equipment was preferred: schools and community ensembles might not to have access to the specialist equipment, or technical skills, required by systems such as LOLA. As such, an early decision was taken to use off-the-shelf equipment, and, where possible, equipment that schools and/or local venues were likely already to own. Likewise, confining the solution to commercially available broadband speeds would enable greater scalable potential. 


\section{Enable large ensembles, but preserve communities of musicians}

In order to preserve existent communities of practice in local venues, a design solution was preferred that connects groups of musicians, rather than individuals. The additional challenges of audio balance and echo avoidance brought about by the presence of multiple musicians per node would therefore need consideration. In order to build large ensembles, a solution that enabled the connection of multiple groups of musicians was also preferred. This again contrasts with the majority of telematic performance projects to date, which tend to connect fewer nodes (often two). Examples of multi-nodal performances exist (for instance, projects by Turnbulance.org and the Online.Arts; see Thorington 2005), but they remain in the minority due to the technical challenges of managing multiple Internet connections.

\section{Enable rehearsal in addition to performance}

Given the aim of working with young and amateur musicians, it was clear that Online Orchestra could not simply be an environment for concert performance: it would also be necessary to enable online rehearsal. As such, an overall ensemble conductor would be needed to lead rehearsals and the performance. It was also decided that standard music notation was preferred, in order to eliminate additional variables/complexities to performers as they rehearsed online, as well as to enable musicians to develop their musicianship skills. Again, there are few precedents for a conductor in the history of telematic performance: Tassine and Verbrugghe's electronic metronome that keeps multiple conductors in time over distances (see Joy 2009: 485), a performance between Stanford and Stockholm where two performers in each node improvised to the pulsing of a 'jellyfish conductor' (Handberg and Jonsson 2005); and Hajdu's Quintet.net, which contains a conductorial layer in its Max/MSP patch (see Hadju and Didkovsky 2009: 400), is partial exception, demonstrating the complexity of enabling a telematic conductor. The decision to pursue a more traditional conductor brought the additional requirement that Online Orchestra supported video communication (the streaming of a visual feed) as well as audio communication.

\section{Enable a connected and immersive musical experience}

Whilst Online Orchestra did not aim during its pilot to measure the extent to which the benefits of ensemble performance might be enabled through a telematic environment, it did use certain principles derived from the literature as benchmarks in design solution decision-making. In particular, drawing from McCaleb (2014) and Keller (2013), the two principles of connection and immersion acted as reference points throughout the project, with the aim of designing a solution in which participants felt (1) connected to other remote musicians and (2) immersed in the overall musical experience. A high-quality audio-visual signal would notionally be crucial to the achievement of these aims.

\section{Online Orchestra - Project overview}

Online Orchestra developed its design solution through action research over a series of eight working groups between October 2014 and July 2015. Kolb's learning cycle (1984) was adopted, in which iterations were made, experience was observed and reflected upon in discussion groups, abstract concepts 

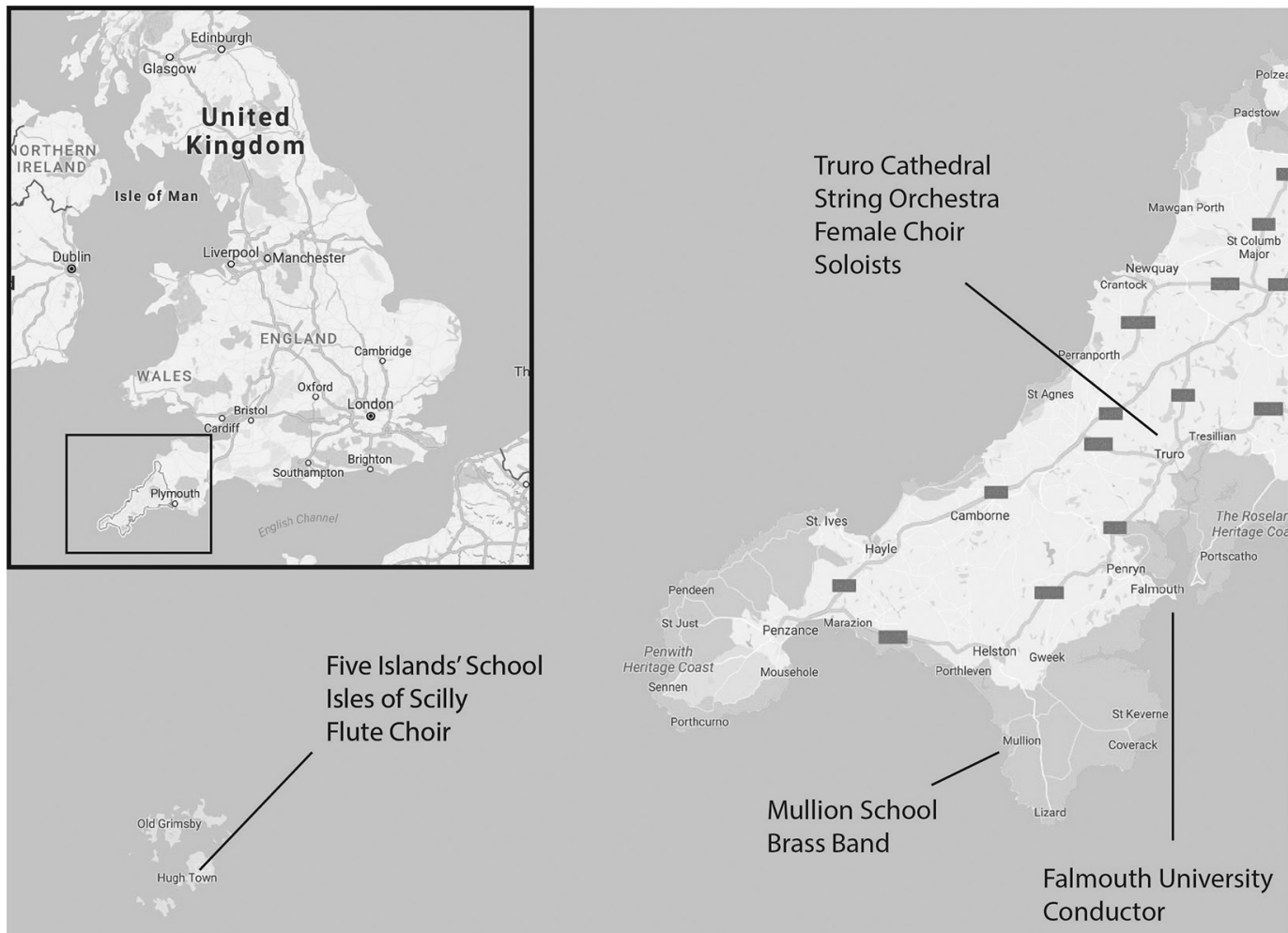

Figure 1: Online Orchestra pilot performance nodes. ${ }^{8}$

based upon reflections were formed and these new concepts were then tested through new iterations. This process was repeated until key variables and potential solutions emerged. In particular, the project team explored (1) software options; (2) computer and peripheral equipment options and usage; (3) approaches to latency; (4) compositional options; and (5) approaches to online rehearsing and directing.

The project culminated in a four-node pilot performance in July 2015. As shown in Figure 1, this involved a conductor at Falmouth University, leading an orchestra of flutes on the Isles of Scilly, brass in Mullion on the Lizard Peninsula and strings, choir and soloists in Truro Cathedral. Musicians performed three new works, commissioned for the performance: In Sea-Cold Lyonesse by John Pickard, Re-Tracing by Jim Aitchison and Spiritus Telecommunitas by Federico Reuben. A video of the performance can be found at www.onlineorchestra.com.

\section{Online Orchestra - Summary of findings}

Details of Online Orchestra's approach to telematic performance are described in subsequent articles in this special issue of the Journal of Music, Technology and Education, including approach to latency (Rofe and Reuben 2017); computing hardware and software (Prior et al. 2017b); peripheral equipment (Prior et al. 2017b; Geelhoed et al. 2017); musical composition (Rofe and Geelhoed 2017);
8. Map exported from Google Maps. 
rehearsing and directing (Hargreaves 2017); and the telematic medium (Prior 2017). An initial exploration of participant performers' experiences is also outlined (Rofe et al. 2017). Key findings from the project can be summarized as follows.

\section{Latency management}

Telematic performance involves latency, in the form of a time delay that results from processing data and sending/receiving it between nodes. Musicians were found to perceive latencies above roughly $30 \mathrm{~ms}$. Given (1) the lower bandwidths available in community contexts, (2) the need for the large data streams involved in video communication and (3) the preference to avoid specialist equipment, it was established that low-latency solutions such as LOLA would not be possible in Online Orchestra. Instead, new software was developed that stabilizes network latency and locks this to a specified musical tempo: latency was matched to the length of a musical beat.

\section{Composing for latency-rich environments}

Given this latency-control programme, composers were able to know with confidence the behaviour of the latency in performance and were consequently able to compose music designed explicitly for this latency-rich environment. By writing scores with latency in mind, composers were able to absorb that latency into the musical materials. As such, the latency stopped functioning as an impediment to performance and instead became a part of the musical content. Orchestral 'sections' (strings, brass, etc.) were assigned to individual nodes within the telematic ensemble, enabling communities of musicians in each location to act as subgroups within the overall orchestra. This preserved the traditional interrelationships of ensemble performance between self, section and orchestra, acting in a telematic context to reinforce local communities of musicians whilst also building new inter-nodal collaboration.

\section{Performing in latency-rich environments}

Given Online Orchestra's latency-control programme, and the production of compositions that absorb latency, participant musicians report no disruptive effects of latency on their ability to perform. In fact, several of the performers who were interviewed post-project were simply not aware of the presence of latency. As such, Online Orchestra was able to adopt a traditional model of rehearsal and performance, in which a conductor used standard beating patterns to lead musicians, who in turn read their parts from scores in standard notation. Participant performers report difficulty adapting to a 2D televisual conductor, but were ultimately able to succeed in this environment. Otherwise, any difficulties they experienced in preparing the performance were similar to those of offline performance: mastering technically complex passages or a preference for certain works. The conductor reports significant improvement on the parts of performers throughout rehearsals, demonstrating the capacity of telematic performance to enable musical development and education.

\section{System design}

As Online Orchestra did not operate at ultra-low latency, the need for specialist equipment was significantly reduced. As such, it was possible to remain 
confined to freely available audio-visual streaming software (JackTrip and VSee) and to low-cost hardware. Musicians each had their own individual microphones, with audio being mixed down in each location before being sent into the network. A single camera was used to capture each location. Return audio from remote nodes was spatialized through independent speakers, each of which was aligned to independent screens showing the visual stream from remote nodes.

\section{Potential of telematic performance and future research}

As indicated in Figure 2, which shows the pilot performance from the perspective of Truro Cathedral, Online Orchestra has established a viable solution that enables large-scale online performance between remote locations. As such, it demonstrates significant potential in enabling access for people living in remote communities to the wide-ranging potential benefits of participating in ensemble music-making. Research is now needed to measure the extent to which these benefits are enabled in a telematic context, and how Online Orchestra's approach might be developed and fine tuned in order to maximize its potential.

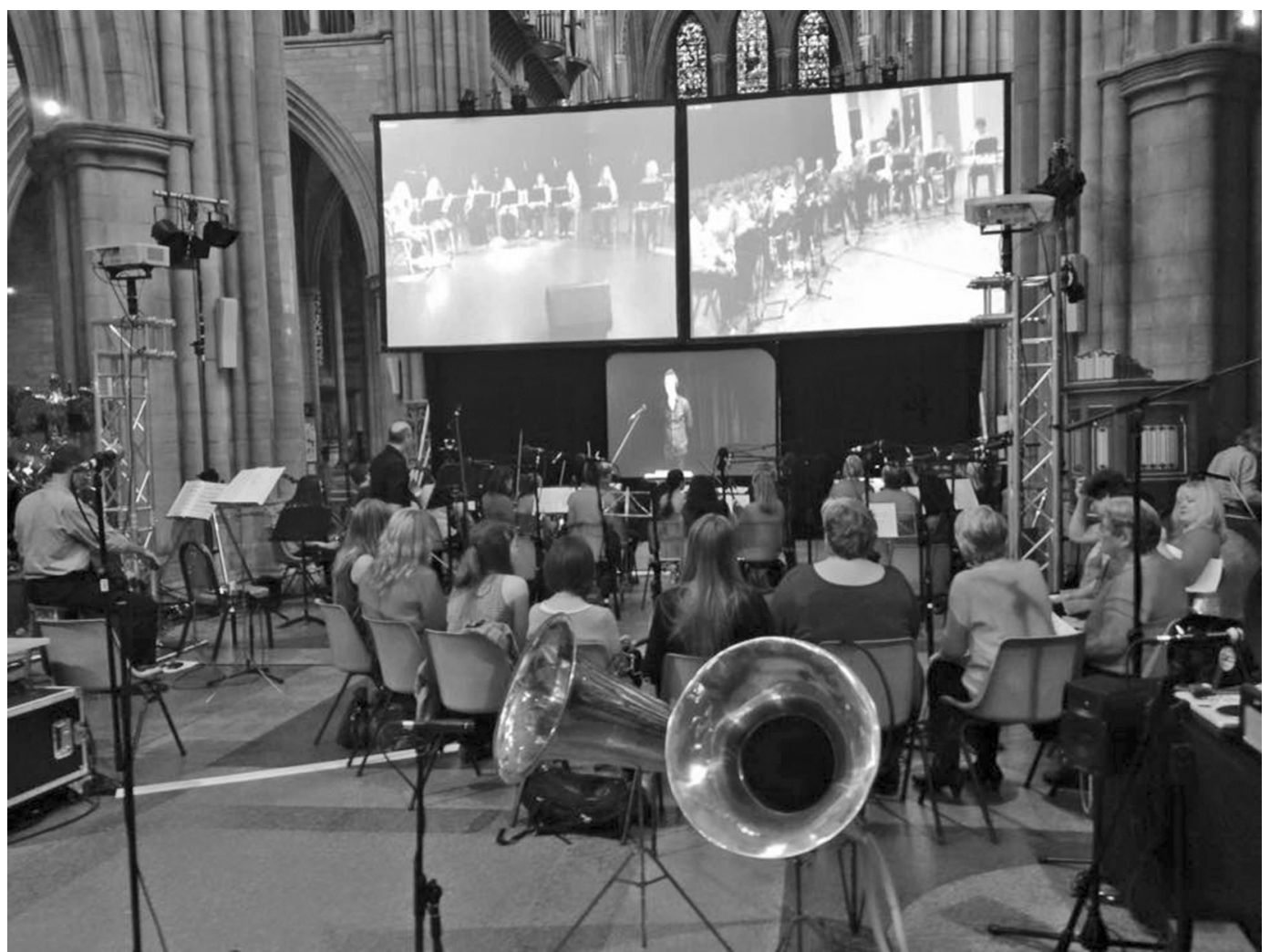

Figure 2: Online Orchestra pilot performance, Truro Cathedral. 


\section{REFERENCES}

Bailey, B. A. and Davidson, J. W. (2002), 'Adaptive characteristics of group singing: Perceptions from members of a choir for homeless men', Musicae Scientiae, 6:2, pp. 221-56.

Bell, D. and Jayne, M. (2010), 'The creative countryside: Policy and practice in the UK rural cultural economy', Journal of Rural Studies, 26:3, pp. 209-18.

Blandford, S. and Duarte, S. (2004), 'Inclusion in the community: A study of community music centres in England and Portugal, focusing on the development of musical and social skills within each centre', International Journal of Research \& Method in Education, 27:1, pp. 7-25.

Braasch, J. (2009), 'The telematic music system: Affordances for a new instrument to shape the music of tomorrow', Contemporary Music Review, 28:4\&5, pp. 421-32.

Carlucci, C. (2012), 'An investigation of social support in adult recreational music ensembles', International Journal of Community Music, 5:3, pp. 237-52.

Chafe, C. and Cáceres, J. P. (2010), 'JackTrip: Under the hood of an engine for network audio', Journal of New Music Research, 39:3, pp. 183-87.

Department for Education (2011), 'The importance of music: A national plan for music', Department for Education, https://www.gov.uk/government/ publications/the-importance-of-music-a-national-plan-for-music-education. Accessed 12 December 2013.

Dillon, S. and Brown, A. (2010), 'Access to meaningful relationships through virtual instruments and ensembles', in Proceedings from the International Society for Music Education (ISME) 2010 Seminar of the Commission for Community Music Activity, 28-30 July 2010, Hangzhou: International Society for Music Education (ISME), pp. 31-34.

Duxbury, N. and Campbell, H. (2011), 'Developing and revitalising rural communities through arts and culture', Small Cities Imprint, 3:1, pp. 111-22.

Föllmer, G. (2005), 'Lines of net music', Contemporary Music Review, 24:6, pp. 439-44.

Geelhoed, E., Prior, D. and Rofe, M. (2017), 'Designing a system for online orchestra: Microphone evaluation and cost-benefit analysis', Journal of Music, Technology and Education, 10:3, pp. 213-30.

Gembris, H. (2008), 'Musical activities in the third age: An empirical study with amateur musicians', Conference Paper at the Second European Conference on Developmental Psychology, Roehampton, http://citeseerx.ist.psu.edu/ viewdoc/download?doi=10.1.1.627.4557\&rep=rep1\&type=pdf. Accessed 4 January 2017.

Gibson, C., Luckman, S. and Willoughby-Smith, J. (2010), 'Creativity without borders? Rethinking remoteness and proximity', Australian Geographer, 41:1, pp. 25-38.

Greene, K. (2007), 'Jam online in real time', MIT Technology Review, https:// www.technologyreview.com/s/407965/jam-online-in-real-time/. Accessed 28 December 2016.

Hadju, G. and Didkovsky, N. (2009), 'On the evolution of music notations in network music environments', Contemporary Music Review, 28:4\&5, pp. 395-407.

Hallam, S., Creech, A., Varvarigou, M. and McQueen, H. (2012), 'Perceived benefits of active engagement with making music in community settings', International Journal of Community Music, 5:2, pp. 155-74.

Handberg, L. and Jonsson, A. (2005), 'Community building through cultural exchange in mediated performance events', in P. Hernwall (ed.), The Virtual - A Room Without Borders?, Södertörn: Södertörn College University. 
Hargreaves, J. J. (2017), 'Notes from the podium of an Online Orchestra', Journal of Music, Technology and Education, 10:2\&3, pp. 277-88.

Henley, D. (2011), Music Education in England: A Review by Darren Henley for the Department for Education and the Department for Culture, Media and Sport, London: Department for Education, https://www.gov.uk/government/ publications/music-education-in-england-a-review-by-darren-henleyfor-the-department-for-education-and-the-department-for-culturemedia-and-sport. Accessed 12 December 2013.

Higgins, L. (2012), Community Music in Practice and in Theory, Oxford: Oxford University Press.

Hugill, A. (2005), 'Internet music: An introduction', Contemporary Music Review, 24:6, pp. 429-37.

Johnson, H., King, A., Savage, J. and Penn, E. (2015), Connect Resound: Research and Development Report, London: Nesta, http://274483.temp-dns.com/ uploads/NYMAZ_for_publication_Final_.pdf. Accessed 23 June 2016.

Jones, P. (2005), 'Music education and the knowledge economy: Developing creativity, strengthening communities', Arts Education Policy Review, 106:4, pp. 5-12.

- (2010), 'Developing social capital: A role for music education and community music in fostering civic engagement and intercultural understanding', International Journal of Community Music, 3:2, pp. 291-302.

Joy, J. (2009), 'Networked Music \& Soundart Timeline (NMSAT) excerpts part one: Ancient and modern history, anticipatory literature, and technical developments references', Contemporary Music Review, 28:4\&5, pp. 449-90.

Keller, P. (2013), 'Musical ensemble performance: A theoretical framework and empirical findings on interpersonal coordination', International Symposium on Performance Studies, http://www.performancescience.org/ISPS2013/ Proceedings/Rows/066Keynote_Keller.pdf. Accessed 15 October 2014.

Kim-Boyle, D. (2009), 'Network musics: Play, engagement and the democratization of performance', Contemporary Music Review, 28:4\&5, pp. 363-75.

Kokotsaki, D. and Hallam, S. (2011), 'The perceived benefits of participative music making for non-music university students: A comparison with music students', Music Education Research, 13:2, pp. 149-72.

Kolb, D. (1984), Experiential Learning: Experience as the Source of Learning and Development, Upper Saddle River, NJ: Prentice-Hall.

Lave, J. and Wenger, E. (1991), Situated Learning: Legitimate Peripheral Participation, Cambridge: Cambridge University Press.

McCaleb, J. M. (2014), Embodied Knowledge in Ensemble Performance, Aldershot: Ashgate.

McHenry, J. A. (2011), 'Rural empowerment through the arts? The role of the arts in civic and social participation in the mid-west region of Western Australia', Journal of Rural Studies, 27:3, pp. 245-53.

McKay, G. and Higham, B. (2011), Community Music: History and Current Practice, its Constructions of 'Community', Digital Turns and Future Soundings, Project Report, Swindon: Arts Humanities Research Council.

McKay, G. and Moser, P. (2005), Community Music: A Handbook, Lyme Regis: Russell House.

Oliver, R. and Reeves, T. (1994), 'Telematics in rural education: An investigation of the use of telematics for the delivery of specialist programmes for students in rural schools', http://ro.ecu.edu.au/ecuworks/6910/. Accessed 21 December 2016. 
Pachini, P., Driolo, C., Buso, N., Allocchio, C. and Parovel, M. (2012), LOLA (Low Latency) Project, Trieste: Conservatorio di musica G. Tartini, http:// www.conservatorio.trieste.it/art/ricerca/progetto-lola-low-latency/lolacase-study.pdf. Accessed 1 December 2016.

Paton, R. (2011), 'Lifemusic: Sounding out university community engagement', International Journal of Community Music, 4:2, pp. 105-20.

Pitts, S. (2005), Valuing Musical Participation, Aldershot: Ashgate.

Pitts, S. E. (2004), 'Everybody wants to be Pavarotti: The experience of music for performers and audience at a Gilbert and Sullivan Festival', Journal of the Royal Musical Association, 129:1, pp. 149-67.

Prior, D. (2017), 'The network as niche', Journal of Music, Technology and Education, 10:2\&3, pp. 289-303.

Prior, D., Reeder, P., Rofe, M., Biscoe, I. and Murray, S. (2017a), 'Designing a system for Online Orchestra: Peripheral equipment', Journal of Music, Technology and Education, 10:2\&3, pp. 197-212.

Prior, D., Reuben, F., Biscoe, I. and Rofe, M. (2017b), 'Designing a system for online orchestra: Computer hardware and software', Journal of Music, Technology and Education, 10:2\&3, pp. 185-96.

Renshaw, P. (2005), Simply Connect: 'Next Practice' in Group Music Making and Music Leadership, London: Paul Hamlyn Foundation.

Roberts, E. and Townsend, L. (2015), 'The contribution of the creative economy to the resilience of rural communities: Exploring cultural and digital capital', Sociologia Ruralis, 56:2, pp. 197-219.

Rofe, M. and Geelhoed, E. (2017), 'Composing for a latency-rich environment', Journal of Music, Technology and Education 10:2\&3, pp. 231-55.

Rofe, M. and Reuben, F. (2017), 'Telematic performance and the challenge of latency', Journal of Music, Technology and Education, pp. 167-83.

Rofe, M., Geelhoed, E. and Hodsdon, L. (2017),'Experiencing Online Orchestra: Communities, connections and music-making through telematic performance', Journal of Music, Technology and Education, 10:2\&3, pp. 147-65.

Schroeder, F. (2009), 'Dramaturgy as a model for geographically displaced collaborations: Views from within and views from without', Contemporary Music Review, 28:4\&5, pp. 377-85.

Thomas, N. J., Harvey, D. C. and Hawkins, H. (2013), 'Crafting the region: Creative industries and practices of regional space', Regional Studies, 47:1, pp. 75-88.

Thorington, H. (2005), 'Breaking out: The trip back', Contemporary Music Review, 24:6, pp. 445-58.

Traub, P. (2005), 'Sounding the net: Recent sonic works for the internet and computer networks', Contemporary Music Review, 24:6, pp. 459-81.

Ultragrid (2015), 'Software for low latency and high-quality video network transmissions', http://www.ultragrid.cz. Accessed 1 December 2016.

Vanderark, S., Newman, I. and Bell, S. (1983), 'The effects of music participation on quality of life of the elderly', Music Therapy, 3:1, pp. 71-81.

Wainwright, D. (2015), interviewed by M. Rofe, Head of Music at Five Islands' School, Isles of Scilly, 20 November.

Wenger-Trayner, B. and Wenger-Trayner, E. (2015), 'Communities of practice: A brief introduction', http://wenger-trayner.com/introduction-to-communities-of-practice. Accessed 30 August 2016.

Weston, D. and Lenette, C. (2016), 'Performing freedom: The role of musicmaking in creating a community in asylum seeker detention centres', International Journal of Community Music, 9:2, pp. 121-34. 
Whitacre, E. (2017), 'Virtual Choir', http://ericwhitacre.com/the-virtual-choir. Accessed 2 January 2017.

Wilson, D., Caulfield, L. and Atherton, S. (2008), Promoting Positive Change: Assessing the Long-Term Psychological, Emotional and Behavioural Effects of the Good Vibrations Gamelan in Prisons Project, Birmingham: Centre for Criminal Justice and Research, http://www.good-vibrations.org.uk/aboutus/annual-report-and-accounts. Accessed 23 November 2016.

\section{SUGGESTED CITATION}

Rofe, M., Murray, S. and Parker, W. (2017), 'Online Orchestra: Connecting remote communities through music', Journal of Music, Technology \& Education, 10:2\&3, pp. 147-165, doi: 10.1386/jmte.10.2-3.147_1

\section{CONTRIBUTOR DETAILS}

Michael Rofe leads the Creative Connected Communities research centre at Falmouth University. His background is in musicology and its links to technology, education and community music, in particular the way in which time is perceived in and through music. Michael was the principal investigator for Online Orchestra.

Contact: Creative Connected Communities, Academy of Music and Theatre Arts, Falmouth University, Penryn Campus, Cornwall, TR10 9EZ, UK.

E-mail: michael.rofe@falmouth.ac.uk

Samuel Murray is a lecturer in music at Falmouth University. He specializes in performance studies and music technology, and is particularly interested in idiomatic organization in music. Samuel was a researcher and technician for Online Orchestra.

Contact: Academy of Music and Theatre Arts, Falmouth University, Penryn Campus, Cornwall, TR10 9EZ, UK.

E-mail: samuel.murray@falmouth.ac.uk

Will Parker is a lecturer in music at Falmouth University, specializing in music technology, sound design and popular music. He works in particular in the areas of field recording, site-specific sound design and composition. Will was a researcher and technician for Online Orchestra.

Contact: Academy of Music and Theatre Arts, Falmouth University, Penryn Campus, Cornwall, TR10 9EZ, UK.

E-mail: will.parker@falmouth.ac.uk

Michael Rofe, Samuel Murray and Will Parker have asserted their rights under the Copyright, Designs and Patents Act, 1988, to be identified as the authors of this work in the format that was submitted to Intellect Ltd. 